
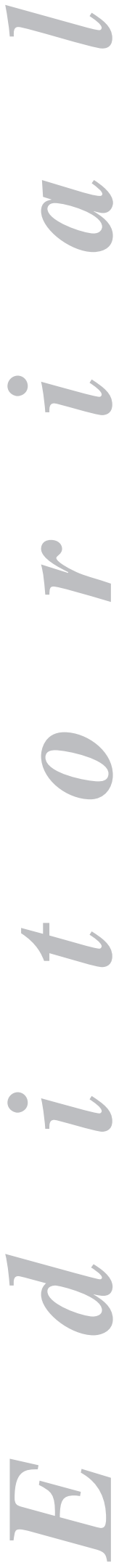

\section{Clinical value of gene NOD2/CARD15 mutations in Crohn's disease}

Crohn's disease (CD) is characterized by chronic inflammation of the gastrointestinal tract. The etiopathogeny of this condition is still unknown. The most widely accepted theory suggests that a dysregulation of the host's immune response against the resident bacterial flora and other intraluminal antigens in genetically susceptible subjects may play a key role in the pathogenesis of tissue damage in $\mathrm{CD}$. Therefore, unknown environmental factors and infectious agents contribute to the development of $\mathrm{CD}$ by acting on underlying genetic grounds. Both genetic and environmental factors are necessary but not sufficient for inducing this disease (1).

Searching for susceptibility genes regarding CD is not an easy task because of the complexity of genetic factors involved, including the absence of a simple Mendelian transmission pattern, incomplete gene penetrance, genetic heterogeneity, and the fact that several susceptibility genes are involved (poligeny) (2).

Recently, three independent groups have simultaneously demonstrated the presence of a susceptibility gene for the development of $\mathrm{CD}$ on chromosome 16, which was initially called NOD2 (nucleotide oligomerization domain 2) and has now been designated CARD15 (C-terminal caspase recruitment domain 15) (3-5). Three polymorphisms (R702W, G908R, and L1007fs) stand out on this gene; the presence of one of these polymorphisms in an individual represents a 2-3-fold increase in the risk for $\mathrm{CD}$, and the presence of two (or only one in homozygosity) a 20-40-fold increase (3).

The discovery of these mutations may not only explain genetic susceptibility in 25-45\% of patients with CD, but also suggest a model to explain the pathogenesis of $\mathrm{CD}$. The protein coded for by gene CARD15 is a receptor recognizing bacterial polysaccharides that regulates NF- $\kappa \mathrm{B}$ (nuclear factor $\kappa \mathrm{B}$ ) and activates proinflammatory cytokine transcription. When CARD15 gene mutations occur $(6,7)$ an aberrant protein is synthesized that changes the immune system's response to germs by reducing monocyte ability to recognize bacteria within the bowel, which results in excessive immune response (7). Race-related differences in the prevalence of CARD15 mutations have also been seen. These mutations are unrelated to CD in at least two populations (Japanese and Korean) $(8,9)$, and prevalence is lower among Afroamericans, Ashkenazi Jews, Scandinavians, and Southern Europeans (10-12). CARD15 gene mutations have been linked with the presence of certain phenotypical characteristics in $\mathrm{CD}$, and identifying these mutations may represent a useful tool for the clinical management of CD in the future.

It may be presently premature to recommend CARD15 genotyping tests in patients with $\mathrm{CD}$ to establish the prognosis of this disease. Most studies associating the presence of mutations in CARD15 with CD location find a higher frequency of these mutations in patients with localized disease in the terminal ileum, a low or intermediate frequency with ileocolic involvement, and an even lower frequency for colic affecta- 
tion alone $(12,13)$. According to some reports, CARD15 mutations show even a reverse association with colic involvement alone, which would have other susceptibility genes in common with ulcerative colitis $(14,15)$. Associations between CARD15 mutations and clinical course are far less consistent, surely because of difficulties in homogenizing the variously used definitions particularly regarding disease behavior, the mean follow-up of patients until their categorization, and the analysis of genetic epidemiologic data (16). Some teams have demonstrated an association between CARD15 and a fibrostenosing and fistulous behavior of CD, which indicates more aggressive disease and associates with a greater need for surgical treatment, primarily ileocecal resection. Other reports find no relationship between a fibrostenosing, fistulous course of disease and CARD15. In some papers the presence of mutation L1007fs is protective against fistula development while predictive of stenosis development, but this behavior is dependant on the ileal localization of CD. These controversial results question the fact that CARD15 mutation genotyping may be a predictive marker for worse prognosis regarding disease behavior (17).

In this issue Barreiro et al. (18) attempt to answer the question whether the presence of major CARD15 mutations is predictive for a need of surgery in CD management. This question remains unanswered. While Ahmad et al. (14) find no association between surgery and CARD15, two studies -one in German patients (19), one in Finnish patients- (20) do find an association between CARD15 mutations and a history of ileocecal resection. In most studies finding an association between CARD15 mutations and a history of surgical management such link disappears when variables most commonly related to CARD15 mutations, including ileal involvement and fibrostenosing-fistulous behavior, are included in the multivariate analysis, a feature not reflected in this paper by Barreiro et al. (18).

Other attractive possibilities regarding the use of CARD15 mutations in clinical practice is the predictive value these may have for the development of extraintestinal manifestations, therapeutic response to infliximab, or a family history of inflammatory bowel disease, all of them aspects that still lack confirmation (16). Furthermore, identifying CARD15 mutations does not seem to be useful in indeterminate colitis when it comes to telling ulcerative colitis from colic CD (17).

CARD15 mutations may also be useful as a screening tool for CD in first-degree relatives of affected patients. It is currently not recommended as it may induce emotional complaints both in patients and their family members, particularly considering that most patients labeled as high-risk will not eventually develop $\mathrm{CD}$, and the fact that prophylactic measures to prevent $\mathrm{CD}$ from developing are not available (21).

Despite the fact that major CARD15 mutations are associated with predisposition to $\mathrm{CD}$ and ileal involvement, doubts persist regarding their usefulness in the prediction of more aggressive disease. Further prospective studies are needed to establish the true influence of CARD15 mutations on this condition's clinical course. Presently we cannot recommend routinely CARD15 mutation genotypying for patients with $\mathrm{CD}$ or their family members, as it is of low added value to standard clinical management. 


\section{REFERENCES}

1. Sartor RB. Clinical applications of advances in the genetics of IBD. Rev Gastroenterol Disord 2003; 3 (Supl. 1): $S 9-17$.

2. Duerr RH. Update on the genetics of inflammatory bowel disease. J Clin Gastroenterol 2003; 37 (5): 358-67.

3. Hugot JP, Chamaillard M, Zouali H, Lesage S, Cezard JP, Belaiche J, et al. Association of NOD2 leucine-rich repeat variants with susceptibility to Crohn's disease. Nature 2001; 411 (6837): 599-603.

4. Ogura Y, Bonen DK, Inohara N, Nicolae DL, Chen FF, Ramos R, et al. A frameshift mutation in NOD2 associated with susceptibility to Crohn's disease. Nature 2001; 411 (6837): 603-6.

5. Hampe J, Cuthbert A, Croucher PJ, Mirza MM, Mascheretti S, Fisher S, et al. Association between insertion mutation in NOD2 gene and Crohn's disease in German and British populations. Lancet 2001; 357 (9272): $1925-8$.

6. Peña AS, Peñate M. Genetic susceptibility and regulation of inflammation in Crohn's disease. Relationship with the innate immune system. Rev Esp Enferm Dig 2002; 94 (6): 351-60.

7. Peñate M, Peña AS. Relevance of the innate immune system. Rev Esp Enferm Dig 2001; 93 (11): 721-39.

8. Sugimura M, Kinouchi Y, Takahashi S, Aihara H, Takagi S, Negoro K, et al. CARD15/NOD2 mutational analysis in Japanese patients with Crohn's disease. Clin Genet 2003; 63 (2): 160-2.

9. Inoue N, Tamura K, Kinouchi Y, Fukuda Y, Takahashi S, Ogura Y, et al. Lack of common NOD2 variants in Japanese patients with Crohn's disease. Gastroenterology 2002; 123 (1): 86-91.

10. Croucher PJ, Mascheretti S, Hampe J, Huse K, Frenzel H, Stoll M, et al. Haplotype structure and association to Crohn's disease of CARD15 mutations in two ethnically divergent populations. Eur J Hum Genet 2003; 11 (1): 6-16.

11. Bairead E, Harmon DL, Curtis AM, Kelly Y, O'Leary C, Gardner M, et al. Association of NOD2 with Crohn's disease in a homogenous Irish population. Eur J Hum Genet 2003; 11 (3): 237-44.

12. Mendoza JL, Murillo LS, Fernández L, Pena AS, Lana R, Urcelay E, et al. Prevalence of mutations of the NOD2/CARD15 gene and relation to phenotype in Spanish patients with Crohn disease. Scand J Gastroenterol 2003; 38 (12): 1235-40.

13. Núñez C, Barreiro M, Domínguez-Muñoz JE, Lorenzo A, Zapata C, Peña AS. CARD15 mutations in patients with Crohn's disease in a homogeneous Spanish population. Am J Gastroenterol 2004; 99 (3): 450-6.

14. Ahmad T, Armuzzi A, Bunce M, Mulcahy-Hawes K, Marshall SE, Orchard TR, et al. The molecular classification of the clinical manifestations of Crohn's disease. Gastroenterology 2002; 122 (4): 854-66.

15. Fernández L, Mendoza JL, Martínez A, Urcelay E, Fernández-Arquero M, García-Paredes J, et al. IBD1 and IBD3 determine location of Crohn's disease in the Spanish population. Inflamm Bowel Dis 2004; 10 (6): 71522.

16. Mendoza JL, Lana R, Díaz-Rubio M. Importance of NOD2/CARD15 mutations in Crohn's disease. Rev Clin Esp 2004; 204 (12): 642-4.

17. Vermeire S. NOD2/CARD15: relevance in clinical practice. Best Pract Res Clin Gastroenterol 2004; 18 (3): $569-75$.

18. Barreiro M, Núñez C, Domínguez-Muñoz JE, Lorenzo A, Barreiro F, Potel J, et al. Asociación entre las mutaciones del gen NOD2/CARD15 con los antecedentes quirúrgicos por enfermedad de Crohn. Rev Esp Enferm Dig 2005; 97 (8): 547-53.

19. Radlmayr M, Torok HP, Martin K, Folwaczny C. The c-insertion mutation of the NOD2 gene is associated with fistulizing and fibrostenotic phenotypes in Crohn's disease. Gastroenterology 2002; 122 (7): 2091-2.

20. Helio T, Halme L, Lappalainen M, Fodstad H, Paavola-Sakki P, Turunen U, et al. CARD15/NOD2 gene variants are associated with familially occurring and complicated forms of Crohn's disease. Gut 2003; 52 (4): $558-62$.

21. Ahmad T, Tamboli CP, Jewell D, Colombel JF. Clinical relevance of advances in genetics and pharmacogenetics of IBD. Gastroenterology 2004; 126 (6): 1533-49. 